The object aimed at is the covering of the country with a network of services, for the most part attached to existing hospitals, and based upon a report issued by the British Medical Association in 1935. The need for such a service will be appreciated when it is stated that more than 201,000 new cases of fractures were treated at voluntary and municipal hospitals in Great Britain during 1935.

\section{Science and the Life of the Community}

Ar the meeting of the General Assembly of the International Council of Scientific Unions last May, a resolution from the Royal Amsterdam Academy of Sciences was adopted (with some modifications) for the appointment of a committee to examine various questions concerned with the practical application of scientific results in the life of the community. That committee has now been constituted as follows: Prof. J. N. Brönsted (Copenhagen), Prof. J. M. Burgers (Delft), Prof. S. Chapman (London), M. Establier (Paris), Prof. B. Nemeč (Prague), M. Francis Perrin (Paris) and Prof. F. J. M. Stratton (Cambridge).

\section{Return of a Large Sunspot}

THE leader sunspot of the extensive group, visible from July 22 until August 4, has returned to view, the following component having in the meantime disappeared. The area of this leader spot was about 1000 millionths of the sun's hemisphere on August 20, and on the following day, although the spot was not very far on the disk, it could be seen with the naked eye. The date of central meridian passage is August $25 \cdot 3$, and the sun's west limb will be reached on August 31. Since the spot is situated in fairly high latitude $\left(33^{\circ}\right.$ north $)$, its drift backwards in longitude is very marked as compared with the angular rotation of the standard meridian (Carring. ton's) used in computing sunspot positions and which is given by the mean of sunspots in solar latitude $15^{\circ}-16^{\circ}$ north and south.

\section{The Night Sky in September}

ON September 23 at $11^{\text {h }}$ U.T., the sun enters the sign Libra (the autumnal equinox). In the latitude of London, the night is then more than $4 \frac{1}{2}$ hours longer than at the time of the summer solstice. The moon is new on September 4 at $22 \cdot 9^{\mathrm{h}}$ and full (the Harvest Moon) on September 20 at $11 \cdot 5^{\mathrm{h}}$. Conjunctions with the planets take place as follows : with Venus on Sept. 2 at $3^{\text {h }}$; with Mercury on Sept. 6 at $5^{\mathrm{h}}$; with Mars on Sept. 12 at $18^{\mathrm{h}}$; with Jupiter on Sept. 15 at $6^{\mathrm{h}}$ and with Saturn on Sept. 21 at $1^{\mathrm{h}}$. An occultation of the star $\xi$ Sagittarii (magnitude $3 \cdot 6$ ) occurs on September 14, the disappearance being visible from Greenwich at $18^{\mathrm{h}} 37 \cdot 5^{\mathrm{m}}$. On September 24, Venus approaches the bright star Regulus. A close appulse of Mars to the 9th magnitude star C.D. 11856 will be visible from South Africa on September 7 at about $17 \cdot 6^{\text {h }}$ U.T. During the month, Finsler's comet in the constellation Virgo continues to move southwards. The following ephemeris is given by Dr. A. D. Maxwell's orbit of the comet :

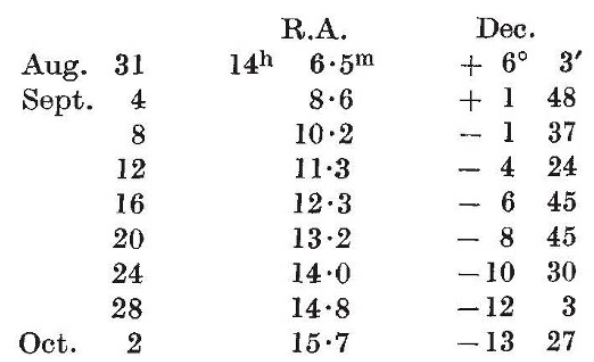

There is a faint comet, discovered by Hubble on August 4, in the south-east region of Aquarius. Positions for Encke's comet (passing from Aries to Triangulum) and for comet Grigg-Skjellerup (passing from Ophiuchus to Serpens) will be found in the "B.A.A. Handbook". $\beta$ Persei (Algol) is now becom. ing well placed in the late evening for observing the variability of its brightness. The change in light is best seen about 1.5 hours before and after the following times: Sept. $5^{\mathrm{d}} 03 \cdot 5^{\mathrm{h}}$, Sept. $8^{\mathrm{d}} 00 \cdot 3^{\mathrm{h}}$, Sept. $10^{\mathrm{d}} 21 \cdot 1^{\mathrm{h}}$, Sept. $28^{\mathrm{d}} 02 \cdot 0^{\mathrm{h}}$ and Sept. $30^{\mathrm{d}} 22 \cdot 8^{\mathrm{h}}$. Meteors, the radiant of which is a little south-east of $\varepsilon$ Persei, may be looked for from September 7 until 15. The night sky during this month offers an unequalled range of various objects within reach of binoculars or small telescopes. In the middle of the month about $2 \mathrm{I}^{\mathrm{h}}$, the cluster of the Pleiades will be seen rising in the north-east. (All times are given in U.T. : add 1 hour to convert to Summer Time.)

\section{Announcements}

THE bicentenary of the birth of Luigi Galvani will be celebrated on October 18-20 by the town and University of Bologna and the Italian Society of Physics.

Dr. MaX WeSTENHoFer, professor of general pathology and pathological anatomy in the University of Berlin, has been elected an honorary member of the Medical Association of Kinesiology at Buenos Aires.

Dr. WeRner KuHN, extraordinary professor of physical chemistry at Carlsruhe, has been appointed full professor at Kiel in succession to Prof. Schwarz, who has been transferred to the chair of chemistry a.t. Königsherg.

Is the famous Bialowieza National Park in Poland, a census of the game animals was carried out during the winter 1936-37, and the following count was made : stags 35, deer 78, wild boar 50, wolf 4 (temporary immigrants), lynx 7 , fox 8 , badger 10 , otter 4 , marten 5 , polecat 19 , hare about 30 , woodgrouse 30 (Kwartalny Biuletyn Informacyjny, 29; 1937).

As informal meetmg to discuss how far scientific workers can help towards the planning of the land of Great Britain, which is one of the important topics of discussion this year at the meeting of the British Association, will be held at Nottingham by the Research Co-ordination Committee (LePlay House, 35 Gordon Square, W.C.1) at the suggestion of the Association of Scientific Workers. 